\title{
Efeito da gordura vegetal parcialmente hidrogenada sobre a incorporação de ácid graxos trans em tecidos de ratos
}

Effect of the partially hydrogenated vegetable fat on the incorporation of trans fatty acids in rat tissues

Céphora Maria SABARENSE ${ }^{1}$

Jorge MANCINI FILHO²

\section{R E S U M O}

A composição lipídica da dieta pode influenciar o perfil de ácidos graxos dos tecidos. O objetivo do presente estudo foi avaliar a incorporação de ácidos graxos trans no fígado e coração de ratos. Dois grupos com doze ratos Wistar recém-desmamados foram alimentados com duas dietas diferentes por oito semanas. Uma das dietas (experimental) foi rica em isômeros trans (33,0\% da fração lipídica) e apresentou quantidades mínimas de ácidos linoléico e $\alpha$-linolênico $(8,0 \%$ e $0,7 \%$, respectivamente, da fração lipídica da dieta), enquanto a outra (controle) foi nutricionalmente adequada. O perfil de ácidos graxos das dietas e dos tecidos foi avaliado por cromatografia gasosa. Houve incorporação de $14,0 \%$ dos ácidos graxos trans no fígado e $8,6 \%$ no coração dos animais. Não foi observado efeito inibitório dos ácidos graxos trans no fígado sobre a formação dos ácidos araquidônico e docosahexaenóico. No entanto, no coração houve uma diminuição significante da concentração do ácido docosahexaenóico, provavelmente como reflexo da deficiência de ácido $\alpha$-linolênico e da incorporação dos trans.

Termos de indexação: ácidos graxos trans, gordura vegetal hidrogenada, ácidos graxos essenciais, ácidos graxos poliinsaturados, cadeia longa, ratos, dieta.

\section{A B S T R A C T}

The lipid composition of the diet can influence the profile of fatty acids the tissues. The objective of this study was to evaluate the incorporation of trans fatty acids in the liver and in the heart of rats. Two groups with

\footnotetext{
1 Departamento de Nutrição e Saúde, Universidade Federal de Viçosa. Av P.H. Rolfs, s/n, 36571-000, Viçosa, MG, Brasil. Correspondência para/Correspondence to: C.M. SABARENSE.E-mail: cephora@ufv.br

2 Departamento de Alimentos e Nutrição Experimental, Faculdade de Ciências Farmacêuticas, Universidade de São Paulo.
} 
twelve weanling Wistar rats each were fed two different diets for eight weeks. One of the diets (experimental) was rich in trans fatty acids (33.0\% of total lipids) and presented minimal amounts of linoleic and $\alpha$-linolenic acids (8.0\% and $0.7 \%$, respectively, of total lipids), while the other (control) was nutritionally adequate. The profile of fatty acids of the diets and tissues was evaluated by gas chromatography. There was an incorporation of $14.0 \%$ of the trans fatty acids in the liver and $8.6 \%$ in the heart. There was no inhibitory effect of the trans fatty acids on the formation of arachidonic and docosahexaenoic acids in the liver. However, a significant decrease in the docosahexaenoic acid concentration was observed in the heart. It was probably a consequence of the deficiency of $\alpha$-linolenic acid and of the incorporation of trans fatty acids.

Index terms: trans fatty acids, hydrogenated vegetable fat, essential fatty acids, long-chain, polyunsaturated fatty acids, rats, diet.

\section{N T R O D U ÇÃ O}

Os ácidos graxos trans são formados durante a hidrogenação dos óleos vegetais. Suas fontes mais importantes na dieta são principalmente os óleos vegetais parcialmente hidrogenados utilizados pela indústria de alimentos e, em menor escala, produtos originados de animais ruminantes ${ }^{1,2}$.

O papel dos ácidos graxos trans no metabolismo humano ainda não está completamente estabelecido. Contudo, evidências experimentais e estudos epidemiológicos não excluem a possibilidade de um efeito negativo no desenvolvimento de doenças cardiovasculares, induzidas pelo consumo elevado dessas substâncias através da dieta ${ }^{3}$.

Estudos clínicos demonstraram que os ácidos graxos trans agem sobre as lipoproteínas, aumentando os teores de LDL e reduzindo a $\mathrm{HDL}$; tais efeitos são potenciais fatores de risco para a saúde cardiovascular ${ }^{4}$.

Os isômeros trans também podem ser incorporados pelos tecidos e metabolizados de maneira semelhante aos ácidos graxos de configuração cis, competindo inclusive pelos mesmos sistemas enzimáticos envolvidos na síntese de ácidos graxos poliinsaturados e eicosanóides 5 .

A síntese de ácidos graxos poliinsaturados ocorre através de reações seqüenciais de dessaturação e alongamento da cadeia do ácido graxo, sendo a primeira dessaturação catalisada pela enzima $\Delta^{6}$ dessaturase, a qual tem como substratos os ácidos oléico, linoléico, $\alpha$-linolênico e, por extensão, seus isômeros trans ${ }^{5}$.

Segundo pesquisa com os isômeros dos ácidos linoléico e $\alpha$-linolênico, os efeitos negativos dos ácidos graxos trans sobre a síntese de ácidos graxos poliinsaturados podem ser minimizados com concentrações adequadas de ácido linoléico, isto é, superiores a $10 \%$ do total de ácidos graxos ${ }^{6}$.

A maior parte dos estudos que avaliam os efeitos dos ácidos graxos trans sobre a síntese de ácidos graxos poliinsaturados utiliza os isômeros do ácido linoléico ou do ácido $\alpha$-linolênico ${ }^{6-8}$. No entanto, os ácidos graxos trans encontrados nas margarinas e em outros produtos elaborados com gordura parcialmente hidrogenada são principalmente os isômeros trans do ácido oléico e, em menor concentração, os isômeros trans do ácido linoléico 9 .

Além do fígado, o coração é um dos tecidos capazes de alongar e dessaturar a cadeia carbônica dos ácidos graxos essenciais, gerando os compostos das famílias $\omega-6$ e $\omega-3$. A dessaturação pelas enzimas $\Delta^{3}, \Delta^{6}$ e $\Delta^{9}$ dessaturases é de grande importância porque esta etapa é controlada pela interação de hormônios com a quantidade dos ácidos linoléico e $\alpha$-linolênico na dieta ${ }^{10}$.

Sob estas perspectivas, realizou-se o presente estudo a fim de verificar a incorporação dos ácidos graxos trans no fígado e coração de ratos e avaliar se o efeito protetor dos ácidos 
graxos essenciais ocorre também em condições mínimas.

\section{MATERIALE MÉTODOS}

Ratos machos Wistar, recém-desmamados, com 21 dias e com peso médio de 57g, foram mantidos em gaiolas individuais, sob temperatura ambiente controlada em $22^{\circ} \mathrm{C}$ e ciclo de claro/escuro de 12 horas.

Os animais foram divididos em dois grupos $(n=12)$, sendo um grupo controle e outro experimental. O consumo da dieta foi verificado diariamente e o ganho de peso dos animais foi calculado a cada cinco dias.

Através dos dados do consumo e dos pesos foi possível avaliar a eficácia alimentar da dieta [ganho de peso (g)/consumo da dieta (g)] e a evolução do peso dos ratos, de cada grupo, durante o período experimental ${ }^{11}$.

A duração total do experimento foi de oito semanas, tempo suficiente para que os ratos alcançassem o peso equivalente ao de um animal adulto, ou seja, aproximadamente 250 a $300 \mathrm{~g}^{8}$. Ao final do experimento os animais foram sacrificados por decapitação; em seguida, os fígados e os corações foram retirados, congelados em nitrogênio líquido e armazenados a $-80^{\circ} \mathrm{C}$, até análise.

A composição das dietas (Tabela 1) foi semelhante à recomendada pelo American Institute of Nutrition ${ }^{12}$, com modificação no conteúdo de lipídios para $150 \mathrm{~g} / \mathrm{kg}$ de dieta. O óleo de soja foi utilizado como fonte lipídica para a dieta controle. A fração lipídica experimental (150g/kg de dieta) foi elaborada misturando-se $15 \mathrm{~g}$ de óleo de soja, $5 \mathrm{~g}$ de óleo de girassol, adquiridos no comércio de São Paulo, SP e 130g de gordura vegetal parcialmente hidrogenada (Sancreme) gentilmente cedida pela Empresa Santista - Alimentos, São Paulo/SP. As proporções foram estabelecidas a partir dos perfis de ácidos graxos dos óleos e da gordura, previamente determinados, a fim de se obter um valor de ácidos
Tabela 1. Composição das dietas.

\begin{tabular}{lc}
\hline Ingredientes & $\mathrm{g} / 100 \mathrm{~g}$ da dieta \\
\hline Amido & 45,00 \\
Sacarose & 10,00 \\
Fibra: celulose microcristalina & 5,00 \\
Caseína & 20,00 \\
Óleos e Gorduras $^{(1)}$ & 15,00 \\
Mistura de Minerais $^{(2)}$ & 3,50 \\
Mistura de Vitaminas $^{(2)}$ & 1,00 \\
Bitartarato de colina & 0,25 \\
\hline
\end{tabular}

(1) Dieta controle: óleo de soja/Dieta experimental: mistura de óleos e gordura vegetal parcialmente hidrogenada. (2) De acordo com o AIN $/ 93^{12}$.

graxos trans elevado (33\% do total de lípides) e valores mínimos de ácidos graxos essenciais para o crescimento e desenvolvimento dos animais experimentais ${ }^{13}$. Obteve-se, então, a partir da mistura dos óleos com a gordura (Tabela 2).

Os lipídios totais dos tecidos foram extraídos em clorofórmio/metanol (2:1) segundo o método de Folch et al. (1957) ${ }^{14}$. Os ácidos graxos foram esterificados de acordo com a técnica descrita por Hartman \& Lago $(1973)^{15}$ e analisados em um cromatógrafo a gás (Cromatógrafo a gás, Shimadzu GC-17 A) equipado com detector de chama e uma coluna capilar de $100 \mathrm{~m} \times 0,25 \mathrm{~mm}$ de sílica (Supelco 2560). Utilizou-se o hélio como gás de arraste a 2,0mL/min com uma razão/divisão da amostra de 50. A programação da temperatura da coluna foi isotérmica a $140^{\circ} \mathrm{C}$ por 5 minutos e com aquecimento a $4^{\circ} \mathrm{C} /$ minuto até $240^{\circ} \mathrm{C}$, permanecendo nesta temperatura por 30 minutos.

As temperaturas do injetor e do detector foram mantidas a $250^{\circ} \mathrm{C}$ e $260^{\circ} \mathrm{C}$, respectivamente. Os ácidos graxos foram identificados através da comparação dos tempos de retenção com padrões autênticos (Sigma $\left.{ }^{\circledR}\right)$.

$\mathrm{Na}$ análise estatística, os resultados foram expressos como média \pm desvio-padrão. O efeito da dieta sobre os tecidos foi avaliado por teste não paramétrico, uma vez que os dados obtidos não se comportam como em uma curva de Gauss. Para a comparação dos ácidos graxos entre os grupos controle e experimental de cada tecido foi 
utilizado o teste de Mann-Withney, consideram como nível de significância para as diferenças $p<0,05$. As análises foram realizadas utilizando o programa para computador INSTAT, versão 2.01 .

\section{RESULTA DOS E DISCUSS Ã O}

A quantidade de ácidos graxos trans na dieta experimental foi de 33\%, caracterizando-a como rica em isômeros trans 6 . O teor de ácido linoléico foi de $8.0 \%$ da fração lipídica, enquanto o de ácido $\alpha$-linolênico foi de $0,7 \%$ da fração lipídica. Os teores dos ácidos graxos essenciais (ácido linoléico e $\alpha$-linolênico) da dieta experi- mental não interferiram no desenvolvimento dos animais, pois o grupo experimental apresentou a mesma curva de ganho de peso do grupo controle (Figura 1). Da mesma forma, não houve diferença no coeficiente de eficácia alimentar $(0,28$ para os dois grupos) nas oito semanas do experimento.

Além disso, as dietas foram isoenergéticas e o consumo alimentar médio dos animais dos dois grupos variou de $8 \mathrm{~g} / \mathrm{dia}$ inicialmente a $20 \mathrm{~g} /$ dia ao final do experimento.

Os resultados encontrados para o peso dos animais foram semelhantes aos obtidos por Al-Othman $(2000)^{11}$. O autor não encontrou diferenças nos ganhos de peso de ratos recém-desmamados alimentados com dietas isoenergéticas, porém com diferentes tipos de gorduras.

Tabela 2. Perfil dos ácidos graxos das fontes lipídicas e dos extratos lipídicos das respectivas dietas dos grupos controle e experimental.

\begin{tabular}{|c|c|c|c|c|}
\hline Ácidos Graxos & Óleo de Soja & Mistura de óleos/GVPH ${ }^{(*)}$ & Dieta Controle & Dieta Experimental \\
\hline C14:0 & 0,07 & n.d. & 0,10 & 0,12 \\
\hline C 16:0 & 10,66 & 11,47 & 11,48 & 11,71 \\
\hline C17:0 & 0,07 & n.d. & 0,08 & 0,08 \\
\hline C18:0 & 3,22 & 13,46 & 3,43 & 12,73 \\
\hline$C 20: 0$ & n.d. & 0,38 & 0,35 & n.d. \\
\hline$C 22: 0$ & 0,43 & n.d. & 0,45 & 0,44 \\
\hline$C 24: 0$ & n.d. & n.d. & n.d. & 0,14 \\
\hline$\Sigma$ Saturados & 14,77 & 25,31 & 14,96 & 25,35 \\
\hline C 16:1 & 0,07 & n.d. & 0,08 & 0,03 \\
\hline C 17:1 & n.d. & n.d. & 0,04 & n.d. \\
\hline C18:1 9c & 24,19 & 18,30 & 23,74 & 13,66 \\
\hline C18:1 10c & n.d. & 4,50 & n.d. & 13,58 \\
\hline C18:1 11c & n.d & n.d. & 0,59 & 2,91 \\
\hline C20:1 & 0,46 & n.d. & 1,14 & 0,08 \\
\hline$C 22: 1$ & 0,46 & n.d. & 0,03 & n.d. \\
\hline$\Sigma$ Monoinsaturados & 24,72 & 22,80 & 25,62 & 30,26 \\
\hline C18:2 & 54,70 & 8,84 & 52,25 & 8,36 \\
\hline C18:3 $\omega-3$ & 5,03 & 0,52 & 4,80 & 0,66 \\
\hline$\Sigma$ Poliinsaturados & 59,73 & 9,36 & 57,05 & 9,02 \\
\hline C18:1 9t & n.d. & 36,80 & n.d. & 31,77 \\
\hline $\mathrm{C} 18: 2 \mathrm{tt}$ & n.d. & 3,07 & n.d. & 0,42 \\
\hline C18:2 tc & n.d. & 0,89 & n.d. & 0,45 \\
\hline C18:2 ct & n.d. & 0,98 & n.d. & 0,31 \\
\hline$\Sigma$ Trans & n.d. & 41,74 & n.d. & 32,95 \\
\hline N.I. & 0,94 & 0,79 & 2,37 & 2,60 \\
\hline
\end{tabular}

${ }^{(*)} \mathrm{GVPH}=$ Gordura vegetal parcialmente hidrogenada; n.d. = não detectados. 


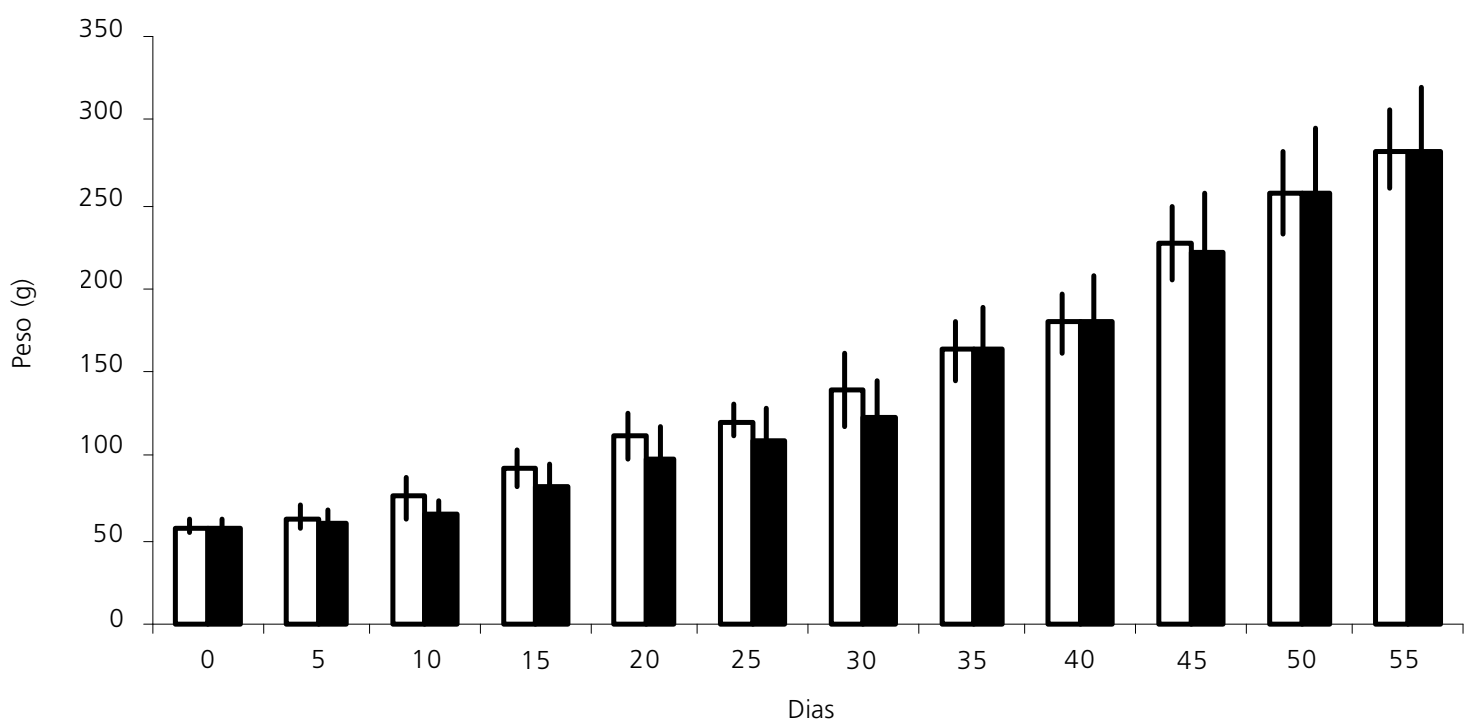

口 Controle $\quad$ Trans

Figura 1. Evolução do ganho de peso dos animais dos grupos controle e experimental.

Tabela 3. Perfil dos ácidos graxos da fração lipídica dos fígados dos animais dos grupos controle e experimental.

\begin{tabular}{|c|c|c|c|}
\hline Ácidos Graxos \% & Grupo Controle $e^{(*)}$ & Grupo Experimental $^{(*)}$ & Nível de significância \\
\hline C 16:0 & $17,27 \pm 0,76$ & $17,85 \pm 1,50$ & n.s. \\
\hline C18:0 & $12,31 \pm 2,27$ & $12,58 \pm 1,15$ & n.s. \\
\hline$\Sigma$ Saturados & $29,57 \pm 2,17$ & $30,43 \pm 1,80$ & n.s. \\
\hline C 16:1 & $0,43 \pm 0,11$ & $1,01 \pm 0,22$ & $p \leq 0,05$ \\
\hline C18:1 9c & $13,71 \pm 1,10$ & $18,02 \pm 0,59$ & $p \leq 0,001$ \\
\hline C18:1 11c & n.d. & $1,94 \pm 0,18$ & n.s. \\
\hline$\Sigma$ Monoinsaturados & $14,14 \pm 1,13$ & $20,59 \pm 1,33$ & $p \leq 0,001$ \\
\hline C 18:2 & $32,75 \pm 2,94$ & $14,71 \pm 0,88$ & $p \leq 0,001$ \\
\hline C18:3 $\omega-3$ & $1,70 \pm 0,19$ & $0,65 \pm 0,10$ & $p \leq 0,05$ \\
\hline$C 20: 2$ & $0,76 \pm 0,19$ & n.d. & - \\
\hline$c 20: 3 \omega-6$ & $0,73 \pm 0,10$ & $1,02 \pm 0,14$ & $p \leq 0,05$ \\
\hline C20:4 & $15,97 \pm 2,67$ & $15,25 \pm 1,35$ & n.s. \\
\hline C22:6 & $3,40 \pm 0,49$ & $3,68 \pm 0,23$ & n.s. \\
\hline$\Sigma$ Poliinsaturados & $55,31 \pm 1,37$ & $33,98 \pm 2,91$ & $p \leq 0,001$ \\
\hline C18:1 $9 t$ & n.d. & $8,50 \pm 0,70$ & - \\
\hline C18:1 10t & n.d. & $3,11 \pm 0,32$ & - \\
\hline C18:1 11t & n.d. & $2,35 \pm 0,22$ & - \\
\hline$\Sigma$ Trans & n.d. & $13,96 \pm 1,12$ & - \\
\hline N.I. & $0,99 \pm 0,32$ & $1,05 \pm 0,33$ & n.s. \\
\hline
\end{tabular}

${ }^{(*)}$ Média \pm desvio-padrão; n.d. = não detectados; n.s. = não significante . 
Sabe-se que, se os ácidos graxos da família $\omega$-3 estão ausentes ou deficientes na dieta, a elongação e a dessaturação dos compostos $\omega-6$ geram significante elevação na formação de ácido docosapentaenóico (C22:5 $\omega$-6); por outro lado, enquanto que, se os ácidos graxos essenciais estão deficientes, o acúmulo será de C20:3 $\omega$-9, isto é, ácido eicosatrienóico, produto do alongamento e dessaturação da cadeia do ácido oléico ${ }^{10,16}$.

Contudo, os fígados dos animais do grupo experimental não apresentaram os ácidos eicosatrienóico $\omega$-9 ou docosapentaenóico $\omega$ - 6 (Tabela 3), sugerindo que a síntese de ácidos graxos poliinsaturados não foi afetada pela quantidade de ácidos graxos essenciais, mesmo estando em quantidades mínimas na dieta.
Outros fatores reforçando esta possibilidade são a presença do ácido eicosatrienóico $\omega-6$ (C20:3), produto intermediário da síntese do ácido araquidônico (C20:4) a partir do ácido linoléico (C 18:2) ${ }^{6}$, no fígado de ambos os grupos, e os teores de ácido araquidônico (C20:4) e docosahexaenóico (C22:6), os quais não apresentaram diferença significativa (Tabela 3).

Vale ressaltar que os ácidos graxos trans presentes no fígado dos ratos alimentados com a dieta experimental foram incorporados da dieta, pois apenas os ruminantes são capazes de sintetizar este tipo de ácido graxo'.

Do total de ácidos graxos trans incorporado foi verificada a presença de isômeros de posição do ácido elaídico (C18:1 9t) com a dupla ligação

Tabela 4. Perfil dos ácidos graxos da fração lipídica dos corações dos animais dos grupos controle e experimental.

\begin{tabular}{|c|c|c|c|}
\hline Ácidos Graxos \% & Grupo Controle $e^{(*)}$ & Grupo Experimental $^{(*)}$ & Nível de significância \\
\hline C 14:0 & $0,47 \pm 0,21$ & $0,41 \pm 0,05$ & n.s. \\
\hline C15:0 & $0,95 \pm 0,12$ & $0,59 \pm 0,11$ & $p \leq 0,05$ \\
\hline C 16:0 & $12,81 \pm 2,74$ & $10,16 \pm 0,54$ & n.s. \\
\hline C17:0 & $0,18 \pm 0,01$ & $0,11 \pm 0,02$ & n.s. \\
\hline C18:0 & $16,53 \pm 0,42$ & $14,42 \pm 0,16$ & n.s. \\
\hline$C 20: 0$ & $0,16 \pm 0,02$ & $0,11 \pm 0,00$ & n.s. \\
\hline$C 22: 0$ & $0,25 \pm 0,02$ & $0,22 \pm 0,01$ & n.s. \\
\hline$\Sigma$ Saturados & $31,35 \pm 3,14$ & $26,02 \pm 0,89$ & $p \leq 0,05$ \\
\hline C16:1 & $0,62 \pm 0,43$ & $0,39 \pm 0,13$ & $p \leq 0,05$ \\
\hline C 17:1 & $0,58 \pm 0,10$ & $0,60 \pm 0,03$ & n.s. \\
\hline C18:1 9c & $12,39 \pm 0,86$ & $17,31 \pm 0,82$ & $p \leq 0,05$ \\
\hline$C 20: 1$ & $0,14 \pm 0,01$ & $0,10 \pm 0,00$ & n.s. \\
\hline$C 22: 1$ & n.d. & $0,40 \pm 0,00$ & - \\
\hline$C 24: 1$ & n.d. & n.d. & - \\
\hline$\Sigma$ Monoinsaturados & $13,64 \pm 1,20$ & $18,47 \pm 0,45$ & $p \leq 0,05$ \\
\hline C18:2 & $27,71 \pm 2,97$ & $15,73 \pm 0,74$ & $p \leq 0,001$ \\
\hline$C 18: 3 \omega-3$ & $0,16 \pm 0,01$ & n.d. & - \\
\hline C18:3 $\omega-6$ & $1,02 \pm 0,16$ & $0,28 \pm 0,03$ & $p \leq 0,001$ \\
\hline$C 20: 4$ & $12,53 \pm 2,72$ & $17,65 \pm 1,30$ & $p \leq 0,05$ \\
\hline$C 20: 5$ & $0,51 \pm 0,12$ & $0,38 \pm 0,04$ & $p \leq 0,001$ \\
\hline$C 22: 5$ & $0,81 \pm 0,23$ & $0,39 \pm 0,10$ & $p \leq 0,001$ \\
\hline$C 22: 6$ & $4,73 \pm 0,60$ & $3,46 \pm 0,25$ & $p \leq 0,05$ \\
\hline$\Sigma$ Poliinsaturados & $47,98 \pm 5,19$ & $41,00 \pm 2,13$ & $p \leq 0,05$ \\
\hline C18:1 9t & n.d. & $8,63 \pm 1,00$ & - \\
\hline $\mathrm{C} 18: 2 \mathrm{tt}$ & n.d. & $0,13 \pm 0,04$ & - \\
\hline$\Sigma$ Trans & n.d. & $8,76 \pm 0,96$ & - \\
\hline N.I. & $7,15 \pm 2,40$ & $8,27 \pm 1,27$ & n.s. \\
\hline
\end{tabular}

(*) Média \pm desvio-padrão; n.d. = não detectados; n.s. = não significante. 
(trans) na posição 10 (3,11\% da fração lipídica) e na posição 11 (2,35\% da fração lipídica). É possível que estes isômeros sejam resultado da $\beta$-oxidação dos isômeros do ácido linoléico presente na dieta experimental (Tabela 2). Resultados semelhantes foram encontrados por Weber et al. (1997) ${ }^{16}$ usando isômeros de posição do ácido oléico e Ratnayake et al. (1994) ${ }^{17}$ com isômeros trans do ácido $\alpha$-linolênico.

A biossíntese dos ácidos graxos passa por uma série complexa de reações integradas nas quais os substratos competem pelas enzimas disponíveis que, por sua vez, são controladas por vários fatores. O destino metabólico dos ácidos graxos endógenos ou da dieta depende do balanço de uma série de reações, tais como: alongamento da cadeia, retroconversão, dessaturação, incorporação em lipídios complexos e $\beta$-oxidação. O produto de cada uma destas reações torna-se um substrato potencial para uma ou outra via. A rota preferencial de cada ácido graxo depende não só da sua estrutura em relação à especificidade de cada enzima, mas também de fatores dietéticos capazes de influenciar o metabolismo, como o tipo e a composição do pool de ácidos graxos que competem por enzimas em comum. Um exemplo desta competição é o oleato, o linoleato e o linolenato e seus respectivos isômeros cis e trans competindo pela $\Delta^{6}$ dessaturase ${ }^{5}$.

Ainda no fígado, a concentração dos ácidos graxos saturados não foi diferente entre os grupos controle $(29,6 \% \pm 2,2)$ e experimental $(30,4 \% \pm 1,8)$. Já os ácidos graxos monoinsaturados apresentaram-se aumentados no grupo experimental $(20,6 \% \pm 1,3)$. Aparentemente esta diferença ocorreu em virtude de uma maior síntese de ácido oléico no grupo experimental, pois na dieta deste encontrava-se em menor proporção do que na dieta controle (Tabela 2). Os ácidos graxos poliinsaturados apresentaram-se com teor reduzido no grupo experimental $(34,0 \% \pm 2,9)$, refletindo somente a menor concentração da dieta, uma vez que não podem ser sintetizados pelos animais.
Quanto à análise do perfil de ácidos graxos do coração (Tabela 4), os resultados indicaram incorporação dos ácidos graxos trans, embora em menor porcentagem (aproximadamente 9\%) do que no fígado (aproximadamente 14\%).

Nesse tecido houve também menor incorporação do ácido linoléico nos animais que receberam a dieta com gordura parcialmente hidrogenada (aproximadamente 16\%) em relação ao controle (aproximadamente $28 \%$ ).

Tanto quanto o fígado, o coração é capaz de dessaturar e alongar a cadeia carbônica dos ácidos graxos essenciais ${ }^{10}$, gerando os compostos das famílias $\omega-6$ e $\omega$-3. O processo de dessaturação/alongamento ${ }^{18}$ pode ser indicado pela razão C20:4 $\omega-6 / C 18: 2 \omega-6$. Nos corações dos animais do grupo controle o valor médio da razão foi 0,45 e no fígado foi 0,49 , enquanto nos tecidos do grupo experimental os valores foram 1,12 e 1,04 para o coração e fígado, respectivamente, sendo portanto superiores aos encontrados no grupo controle. Estes resultados indicam que os potenciais de conversão dos ácidos essenciais em ácidos graxos poliinsaturados do fígado e do coração do mesmo grupo não são diferentes entre si e respondem, de maneira semelhante, ao estímulo das dietas. No entanto, os dados sugerem que pode haver uma maior eficiência em sintetizar os ácidos graxos poliinsaturados nos tecidos dos animais do grupo experimental, apesar da menor concentração do ácido linoléico na dieta.

Uma hipótese para explicar tais resultados seria a de que os tecidos capazes de metabolizar ácidos graxos poliinsaturados de cadeia longa podem regular a acilação dos triacilgliceróis e fosfolípides a fim de manter as suas propriedades físico-químicas ${ }^{7,8}$.

Uma dieta deficiente em ácido $\alpha$-linolênico (C18:3 $\omega$-3) resulta em menor síntese de C22:6 $\omega$-3 e maior síntese de C22:5 $\omega$-6 nos tecidos ${ }^{13}$. Nos corações dos animais do grupo experimental houve uma redução na síntese de C22:6 $\omega$-3 $(p<0,05)$ como conseqüência da baixa concentração de C18:3 $\omega-3$. Apresentaram também menor síntese de C22:5 $\omega-6$ quando 
comparado com o grupo controle (Tabela 3), provavelmente por causa da menor concentração de C18:2 $\omega$-6 na dieta experimental (Tabela 2).

Os ácidos graxos essenciais, como substratos para a síntese de ácidos poliinsaturados, utilizam o mesmo sistema enzimático no processo de dessaturação e alongamento das cadeias carbônicas. O grau de afinidade para as enzimas envolvidas nesse processo é determinado pela estrutura molecular, bem como pela concentração dos substratos; desta forma, uma menor oferta de ácido linoléico provoca um direcionamento das reações no sentido de metabolizar este ácido ${ }^{10}$.

Os teores de ácidos graxos saturados e poliinsaturados dos corações dos animais do grupo experimental apresentaram-se inferiores aos do grupo controle, indicando que a incorporação dos ácidos graxos trans altera o perfil dos ácidos graxos nesse tecido.

\section{CONCLUSÃ O}

Verificou-se, neste trabalho, que os ácidos graxos trans, ao serem incorporados, alteram as proporções entre os ácidos graxos saturados, monoinsaturados e poliinsaturados e que a porcentagem de incorporação dos ácidos graxos trans varia entre os tecidos, apresentando-se maior no fígado em comparação com o coração.

Os resultados obtidos confirmam que os efeitos da incorporação dos ácidos graxos trans são diferentes para o fígado e para o coração, em virtude da necessidade de um perfil de ácidos graxos para a manutenção das propriedades metabólicas específicas de cada tecido.

A incorporação dos ácidos graxos trans da dieta reforça a necessidade de aprofundar os estudos sobre os efeitos dos ácidos graxos trans para a biossíntese de outras classes de lipídios, tais como os fosfolípides, tendo em vista a sua importância para a manutenção das propriedades das membranas celulares.
A GRADECIMENTOS

Nossos agradecimentos à FAPESP e CAPES/PICDT.

\section{RE FER Ê NCIAS}

1. Fritsche J, Steinhart H. Analysis, occurrence, and physiological properties of trans fatty acids (TFA) with particular emphasis on conjugated linoleic acid isomers (CLA) a review. Fett/Lipid 1998; 100:190-210.

2. Pokorný J. Trans unsaturated fatty acids in fats and oils. Eur J Lipid Sci Technol 2000; 102:630-2.

3. Meijer GW, Van Tol A, Van Berkel THJC, Westrate JA. Effect of dietary elaidic versus vaccenic acid on blood and liver lipids in the Hamster. Atherosclerosis 2001; 157:31-40.

4. Hudgins LC, Hirsch J, Emken EA. Correlation of isomeric fatty acids in human adipose tissue with clinical risk factors for cardiovascular disease. Am J Clin Nutr 1991; 53:474-82.

5. Mahfouz MM, Kummerow FA. Hydrogenated fat high in trans monoenes with an adequate level of linoleic acid has no effect on prostaglandin synthesis in rats. J Nutr 1999; 129:15-24.

6. Bysted A, Gunhild H, Lund P. Influence of moderate amounts of trans fatty acids on formation of polyunsaturated fatty acids. J Am Oil Chem Soc 1998; 75:225-34.

7. Larqué E, Zamora S, Gil A. Dietary trans fatty acids affect the essential fatty-acid concentration of rat milk. J Nutr 2000; 130:847-51.

8. Löi C, Chardigny JM, Almanza S, Leclere L, Ginies C, Sébédio JM. Incorporation and metabolism of dietary trans isomers of linolenic acid alter the fatty acid profile of rat tissues. J Nutr 2000; 130: 2550-5.

9. Houwelingen ACV, Horsntra G. Trans fatty acids in early human development. World Rev Nutr Diet 1994; 75:175-8. 
10. Uauy R, Valenzuela A. Marine oils: the health benefits of $n-3$ fatty acids. Nutrition 2000; 16 : 680-4.

11. Al-Othman AA. Growth and lipid metabolism responses in rats fed dietary fat sources. Int J Food Sc Nutr 2000; 51:159-67.

12. Reeves PG, Nielsen FH, Fahey JR GC. AIN-93 purified diets for laboratory rodents; final report of the American Institute of Nutrition ad hoc writing committee and the reformulation of the AIN-76 rodent diet. J Nutr 1993; 123(11):1939-51.

13. Bourre JM, François M, Youyou A, Dumont O, Pinotti M, Pascal $G$, et al. The effects of dietary $\alpha$-linolenic acid on the composition of nerve membranes, enzimatic activity, amplitude of electrophysiological parameters, resistance of poisons and performance of learning tasks in rats. J Nutr 1989; 119:1880-92.

14. Folch J, Lees M., Sloane-Stanley GH. A simple method for the isolation and purification of total lipids from animal tissues. J Biol Chem 1957; 226:497-509.

15. Hartman L, Lago BCA. Rapid preparation of fatty methyl esters from lipids. Lab Pract 1973; 22: 475-77.

16. Weber N, Vosmann K, Brühl L, Mukherjee DK. Metabolism of dietary petroselinic acid; a dead-end metabolite of desaturation/chain elongation reactions. Nutr Res 1997; 17:89.

17. Ratnayake WMN, Chen ZY, Pelletier G, Weber D. Occurrence of 5c,8c,11c,15T-eicosatetraenoic acid and other unusual polyunsaturated fatty acids in rats fed partially hydrogenated canola oil. Lipids 1994; 29:707-14

18. Bourre JM, Pinotti M, Dumont O, Pascal G, Durand G. Dietary linoleic acid and polyunsaturated fatty acids in rat brain and other organs. Minimal requirements of linoleic acid. Lipids 1990; 25: 465-72.

Recebido para publicação em 9 de maio e aceito em de 20 de dezembro de 2003. 